\title{
Corporate Governance Crisis Caused by Lack of Business Ethics
}

\section{(Organizational Behavior Analysis of LIBOR Scandal)}

\author{
Haoran $\mathrm{Xu}^{1, *}$ \\ ${ }^{1}$ Alliance Business School, University of Manchester, Manchester, UK \\ *Corresponding author.Email: haoran.xu-2@postgrad.manchester.ac.uk
}

\begin{abstract}
Firstly, based on the fraud of Barclays Bank in the LIBOR manipulation incident, this paper analyzes the role of behavioral and psychological factors such as morality, the principle of reciprocity, conformity and obedience to authority in misconduct. Secondly, it analyzes the internal culture of commercial banks and the external culture of the overall financial industry under the background of the event, as well as the role of social structure and informal social relations in LIBOR fraud at that time. Finally, according to the personal point of view, this paper puts forward the responsibilities of individuals, organizations and governments in preventing fraud, and puts forward measures to prevent fraud such as LIBOR manipulation from these three levels.
\end{abstract}

Keywords: Fraud prevention, LIBOR scandal, morality, leadership, responsibility.

\section{INTRODUCTION}

In 2008, with the bankruptcy of Lehman Brothers, the subprime mortgage crisis broke out in the United States. During this period, Barclays Bank quickly became a member of the world's first-class investment banking team by acquiring part of Lehman Brothers' North American business. However, due to the deterioration of the external financial environment, the internal capital flow and overall financial situation of Barclays Bank have problems. In addition, Barclays Bank ignored the construction of internal control system while its business developed rapidly, which eventually triggered a financial scandal that shocked the world - LIBOR manipulation incident. In this incident, on the one hand, traders repeatedly affected LIBOR by manipulating interest rate quotations to earn large profits. On the other hand, Barclays Bank has artificially lowered its interest rate quotation data to cover up its lack of liquidity, thereby falsely improving its competitiveness.

In the corporate governance of Barclays Bank, a series of corporate governance errors caused by the moral crisis led to the manipulation of LIBOR. In the follow-up investigation, it was found that many large commercial banks had similar manipulation. Such misconduct not only damages the rights and interests of investors, but also greatly reduces the social trust in the financial industry. Since then, terms such as conduct risk have become a new buzzword.

This paper mainly studies the individual and organizational misconduct in the LIBOR manipulation case. The second part of paper analyzes the role of behavioral and psychological considerations, including morality, reciprocity, conformity and obedience. The third part discusses the role of relationships and informal networks under the unequal social structure in Britain. The fourth part attempts to explore and analyze the mechanism between misconduct risk and cultural capital. The fifth part provides a feasible solution for preventing LIBOR fraud. Finally, this paper analyzes the respective responsibilities in corporate governance and the prevention of misconduct from the levels of individuals, organizations and governments.

\section{ROLE OF BEHAVIORAL AND PSYCHOLOGICAL CONSIDERATIONS}

\subsection{Morality}

The moral judgment of the company's senior management as well as the moral leadership plays an important role in interest rate operation events. According to the four-component model, Barclays' management failed to make moral judgment [1]. 


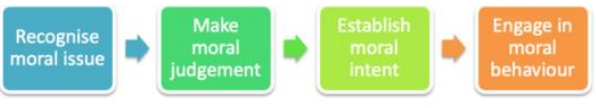

Figure 1. The Four-component Model

Source: Moral development: Advances in research and theory.

According to the view of situational differences in moral relativism, in the context of the deterioration of the financial environment, the leadership is affected by utilitarianism. They believe that it is the correct ethical behavior to earn as much profit as possible for shareholders, but they ignore the unethical operations in the process, that is, using illegal means to manipulate interest rates to earn benefits and maintain the company's external financial image.

\subsection{Reciprocity}

In the realm of social psychology, social exchange theory explains the change and development of the quality of relationships between people, and the norm of reciprocity followed in this process is an important prerequisite for the continuous generation of social exchange [2]; [3].

In the LIBOR manipulation case, reciprocity plays a negative role. Negative reciprocity is a highly selfinterested behavior, under which the purpose of the individual is to protect his own interests and maximize his own interests as much as possible. When negative reciprocity occurs, the exchanging party believes that they possess special rights, thus treating others unfairly. In particular, traders colluded with quoters, and even used emails to record and manipulate negotiations, so that they could easily obtain huge profits. Even more, in order to obtain LIBOR quotations conducive to their risk exposure, some female traders did not hesitate to seduce the quotation tellers, and manipulated the three-month and sixmonth Swiss Franc LIBOR quotations three times between May 5 and 14, 2009. Although it is expressly stipulated that the trading department and the quotation department are strictly separated, workplace deviant behaviors keeps emerging.

\subsection{Conformity}

Conformity is a kind of obedient psychological tendency, which is also a deviation phenomenon in personal psychology. It can be used to explain the situation: even though individuals know that the claim of the majority is wrong, they may still obey the majority's opinions [4].
In the LIBOR scandal, conformity of Barclays Bank employees plays a great negative role. On one hand, the minority is subordinate to the majority. Evidence shows that many traders privately manipulated LIBOR interest rates before the scandal broke out. In this sense, other traders had to acquiesce and obey the operation in order to avoid conflict with most colleagues. On the other hand, traders are affected by the impact of psychological uncertainty demand. Since submitting interest rates is only the work of bank employees, whether to manipulate interest rates is not clear right or wrong for the work itself. When most people are operating interest rates in the general environment and employees do not know how to choose, it is easy to fall into conformity. This is especially true for the young and inexperienced employees.

\subsection{Power and Obedience to Authority}

The psychological phenomenon of obedience to authority has a fundamental influence on people's choice of moral concepts. It often makes people violate human conscience based on the concept of obedience to authority, choose completely immoral behavior, and rely on loyal moral beliefs to support their wrong behavior. According to Milgram experiment, there is a basic tendency of obeying authority in human nature [5]. If the management wants to achieve effective corporate governance, the authority obedience effect must be weaken.

However, some individual contributions are of greater importance than others, especially those of senior bank managers [6]. The investigation of Barclays Bank found that some traders' attempts to manipulate interest rates were actually done under the instructions of senior managers. For example, the boss of Barclays Bank, Bob Diamond, enjoyed a high degree of authority and had great discretion over the company's personnel and property. At the instigation of Paul Tucker, the deputy governor of the Bank of England, Bob decided to lower interest rates, and then instructed former chief operating officer Jerry del Missier to lower the price of LIBOR. Under the pressure of a corrupt culture, even an honest submitter can only start making false LIBOR submissions. Participating in such an approach, he risks the erosion of his moral character, undermining his disposition to act honestly [6]. 


\section{SOCIAL STRUCTURE AND ROLE OF RELATIONSHIPS AND INFORMAL NETWORKS}

\subsection{Social Structure}

The widening gap between the rich and the poor and the shrinking middle class are the practical problems facing the British social structure. The social structure is very unequal, which is reflected in uneven distribution of opportunity and life, polarization, social exclusion, elites with too much power, etc. [7].

Since the middle of the 20th century, the rapid growth of the middle class has once become the fundamental driving force for economic development. However, after the financial crisis, the world's major capitalist countries experienced stagnant economic growth, abnormally high unemployment rates, and widening gaps between the rich and the poor, which in turn led to the shrinking of the middle class. The OECD survey shows that in 2012, the richest $10 \%$ controlled half of all total households, the richest $1 \%$ owned $18 \%$, and the poorest $40 \%$ only accounted for $3 \%$. This is the largest gap between rich and poor since 1986 [8]. According to a 2011 research report issued by the British Institute of Finance, by 2013, after deducting inflation, the income of the British middle class will fall by $7 \%$, which is the largest decline in 35 years.

Income inequality has led to the polarization of wealth distribution and split the social structure. The fruits of capitalist economic development did not benefit the entire population, but mainly tilted towards the wealthy class. According to the Organization for Economic Co-operation and Development (OECD), Britain's inequality is more than three-quarters of the major industrialized countries [9]. The main cause of income inequality is attributable to the salary system of large companies. The income of shareholders and executives has grown rapidly, but the income of ordinary employees has stagnated, and even one-fifth of the population is below the poverty line.

Moral injustice caused by widespread material inequality [7]. The high incomes of bankers have made every blemish in the European and American banking industry infinitely magnified by the public, thereby exacerbating the tension between the rich and the poor. When capital and wealth are constantly transferred to the hands of oligarchs and monopolies, the majority of the people make little profit, which will inevitably undermine democracy. In the United Kingdom, due to the economic downturn, large-scale unemployment and cuts in social welfare have triggered large-scale mass movements, such as The British riots in 2011. After the Barclays Bank scandal was exposed, British bankers were unanimously bombarded by ordinary people, economists and Prime Minister Cameron. The intensity of the scandal may be far beyond the banks' expectations. It can be said that since the outbreak of the financial crisis, bankers who enjoy huge salaries and bonuses have become objects of contempt by the European and American public.

\subsection{Relationships and Informal Networks}

In an enterprise or organization, Informal networks is different from the management system architecture completely defined by the leader. It is composed of a group of individuals with free internal connections [10]. Individuals within these informal networks often have the same characteristics, such as belonging to the same department of the company and having common interests and goals. Traditional formal social networks usually rarely reflect the working relationship between people. On the contrary, informal social networks are more flexible and collaborative. Therefore, internal members have closer social relations. They are easier to help each other and share resources.

First, Barclays Bank is not alone in manipulating interest rates at the industry level. In follow-up investigations, it was found that 16 large international banks such as Citigroup, JPMorgan Chase and Deutsche Bank were involved in manipulating LIBOR interest rates. This illegal operation turned out to be a unified behavior in the industry. This proves that the leaders of the major banks have established an informal social network, and everyone has reached a consensus on manipulation through the social network.

Second, at the management level, the Bank of England Deputy Governor Tucker has close ties with Barclays' CEO Diamond. The long-term regulatory negligence of the British authorities indicating that the CEO of Barclays has also established an informal social network with senior executives of the national regulatory agency.

Third, at the trader level, there is also an informal social network within employees. This social network has played a role in promoting their interest rate manipulation behavior. A large amount of evidence shown in the survey shows that some traders have worked together to manipulate interest rates for a long time. Even unscrupulously used e-mail to negotiate and manipulate. This collaborative behavior and freedom of action are consistent with the characteristics of informal social networks. 


\section{CULTURE OF THE BANKS AND INDUSTRY}

\subsection{Culture of the Financial Industry}

Some scholars regard the organizational culture of the bank as the main driver of misconduct [11]. The LIBOR case shows that misconduct is gradually changing from the individual level to the organizational level. The interest groups are huge, with more than 20 banks involved, including Citigroup, JPMorgan Chase, Deutsche Bank, HSBC, and Royal Bank of Scotland, indicating that there is an improper culture and ethos in the entire financial industry.

First of all, the value of maximizing the profit and the culture of greed prevail in the banking industry. With the rapid development of the financial industry, banks no longer rely solely on the profit model of borrowing deposits and lending to earn interest margins. Instead, banks actively participate in financial innovation, especially the development and trading of derivatives. The highly leveraged nature of such transactional business enables banks to earn huge excess returns from it. Therefore, the value of chasing profits is recognized and encouraged by the directors, senior managers and even shareholders of major financial institutions. The culture of greed spread within the industry, and motives for illegality and collusion emerge. Banks are obsessed with the excess returns brought about by derivatives trading, and they indulge and even encourage traders to pursue greater profits regardless of risk. Since the salaries of bank executives and traders are closely related to their performance, in order to get higher year-end dividends, they will not hesitate to get involved in higher-risk transactions.

Second, utilitarianism has led to a gambling culture. The management of the large banks headed by Barclays is deeply influenced by utilitarianism and is obsessed with the pursuit of profit, ignoring the essence of the financial industry as a service industry. Therefore, the bank's operating model puts its own interests first and the interests of customers second. Some regulators described Barclays as having a gambling culture and betting on public interest.

Finally, the lack of supervision has contributed to widespread fraud in the banking industry. As an industry with the fastest pace of innovation, the complexity and professionalism of financial activities

\footnotetext{
${ }^{1}$ The five guiding principles of Barclays Bank include winning together, best people, customer and client
}

make it difficult for supervisory authorities to work. According to Martin Taylor, the former CEO of Barclays Bank, systemic fraud is widespread in the banking industry, and the lack of internal control and weak supervision have actually contributed to these actions. Under normal circumstances, in order to ensure the authenticity of LIBOR's quotes, there should be barriers to information exchange between traders and quoters. This is the so-called "Chinese Wall" rule, but most large financial institutions have not followed this rule. Specifically, Barclays Bank did not start to set up the "Chinese Wall" until December 2009. In the five years before this, a total of 14 traders have tried 257 times to bribe quoters to manipulate interest rates. Regarding such almost public violations, the bank has not taken any measures to prevent or control it, exposing the institutional loopholes in internal control that are common in the banking industry.

\subsection{Culture of Barclays Bank}

Organizational culture and ethical decisionmaking are deeply intertwined. The behavior changes by culture are non-language drived. People look for clues from the behavior of people around them to determine how to behave and interact to form their own behavior [12]. Usually, in a bank, employees will carefully observe their colleagues, especially bank leaders (such as department heads, presidents, etc.), to learn the standards of behavior.

First, Barclays Bank lacks internal corporate culture construction. Employees have not formed a unified and positive core value. Although CEO John Varley proposed Barclays' five guiding principles ${ }^{1}$ in 2005, he did not attach importance to the promotion and application of the principles in banks. In fact, employees are not clear about the company's guiding principles, which directly leads to the lack of ethical awareness of the company's employees, making unethical behavior become common.

Second, the capital of culture in Barclays Bank has a negative damage mechanism. The capital of culture is an intangible asset, an organizational transaction behavior at the value level [13]. Generally, in organizations with higher levels of cultural capital, the risk of misconduct is lower because the structure, process, and business model are consistent with the ethical standards and values promoted by the company [14]. On the contrary, low-level cultural capital will cause damage to all aspects of bank operations and

focus, pioneering, and trusted. 
governance. In Barclays Bank, the negative effects are embodied in: (1) Silence effect. When honest traders find misconduct, they tend to not speak freely. Therefore, the senior management or the board of directors will not detect illegal activities until they are discovered by the authorities. (2) Short-term effects. Traders only focus on short-term results, that is to say, high salary and bonus. Moreover, traders have low loyalty to the bank, or require the bank to increase its commitment to long-term value. These behaviors have profoundly damaged the bank's existing cultural capital, and they often occur to senior management and compliance personnel of the bank, without the personnel department even knowing it. (3) Individualism. Individualistic organizational cultures often produce negative reciprocity. The purpose of traders is to protect their own interests and maximize their own interests as much as possible.

\section{MEASURES TO PREVENT LIBOR FRAUD}

\subsection{Individual Level}

From the perspective of employees, it is necessary to enhance employees' sense of morality and sense of responsibility and enhance their proactiveness in implementing internal control measures. The internal control system is not set for a certain individual, its main function is to set the rights and responsibilities in the business. As long as people are in a certain position, they must unconditionally accept the internal control constraints that match the position. This concept is conducive to enhancing the proactiveness of employees in implementing internal control measures. For the makers and supervisors of the internal control system, the establishment of this concept is of great significance for improving internal control measures and avoiding human errors and fraud.

From a management perspective, the ethical leadership of management needs to be improved. Moral leadership theory emphasizes the importance of integrity and ethical behavior, and emphasizes the consistency of values and behavior. Correct ethical leadership can have a positive influence mechanism on the organization itself and its employees. In the LIBOR incident, the lack of personal ethics of the leaders of Barclays Bank led to a decline in moral leadership and had a negative impact on the ethics of the organization's employees.

Therefore, senior management should lead by example, provide role models and demonstrate their commitment and determination to promote a good banking culture and values. For example, senior management can participate in cultural and ethical training and examinations. In this way, when employees face ethical dilemmas, they will form an emulation mechanism and make the same judgments as leaders.

In addition, the expansion of the power of Barclays Bank's senior management has weakened the effectiveness of corporate governance, and internal control lacks effective restraint on senior management. Therefore, all employees of the enterprise must establish the concept that everyone is equal before the internal control regulations. The implementation of the internal control system requires the participation and compliance of all personnel in the organization. Everyone is equal and applicable in internal control.

\subsection{Organizational Level}

Establish an effective bank governance framework system from top to bottom to ensure a unified cultural value to prevent LIBOR fraud. Barclays Bank can establish a cultural committee specifically responsible for cultural construction under the authorization of the board of directors. And establish the corresponding supervision and audit mechanism of the Culture Committee, and require it to take the responsibility of cultural orientation. For example, financial institutions such as the US Investors Bank \& Trust have set up a Chief Cultural Officer (CCO) to be responsible for the management of the company's cultural values and prevent the occurrence of misconduct. Therefore, Barclays should use a variety of methods to promote corporate culture within the company.

\section{(1) Cultural Transmission}

First, Barclays Bank should conduct a unified cultural transmission education for the company's employees after establishing the spirit, philosophy and core values of the company. For example, new employees receive corporate culture training after entering the company, printing and distributing company management manuals to each employee, and the management of the company collectively conveys corporate values to the employees in the company's collective meetings. Subtly make employees familiar with the company's corporate culture, and then generate a sense of identity.

(2) Set good models

Barclays Bank can internally select employees who fully meet the company's guiding principles for promotion or excellent employee recognition to set models. Making full use of the demonstration effect, 
and visualize the concept. On the one hand, doing so can help employees understand and recognize the corporate philosophy and values from the behavior of typical characters, so as to make behaviors that are beneficial to the company. On the other hand, employees who did not originally agree with the corporate philosophy directly imitate typical behaviors, so that they can make behaviors that the company needs.

\section{(3) Improve the long-term remuneration mechanism}

Performance evaluation is a cognitive process that helps employees make judgments in line with company values [15]. A sound remuneration mechanism should comprehensively evaluate the various tasks of employees, so that their behavior is consistent with the company's long-term development strategy.

The compensation mechanism of financial institutions should not be excessively directly linked to short-term sales performance. Judging from the salary reform trend of mainstream banks in Europe and the United States, the bank's reward system (including employee recruitment, performance management, salary and promotion system) is gradually breaking through the link with performance, and it will also consider employees' adherence to bank culture and behavior standards to avoid facilitating Employees only care about their own short-term interests while sacrificing the interests of customers or ignoring the long-term interests of the bank's stability and safety.

In addition, before the LIBOR incident, there was little evidence that Barclays Bank's performance appraisal process effectively used company values to drive employee behavior. For example, although Barclays Bank defines trusted as a key guiding principle, the performance evaluation parameters used to determine employee integrity are defined vaguely and without divergence. Therefore, Barclays Bank should modify or reformulate the corresponding performance evaluation system in accordance with the established guidelines, and use the coercive force of the system to make employees accept the corporate philosophy and values, thereby generating favorable corporate behaviors.

(4) Incentive mechanism and restraint mechanism

Before the interest rate manipulation incident, Barclays Bank did not establish a complete incentive mechanism and restraint mechanism for the ethical standards of the company's employees. It makes the employees' own moral principles fuzzy and easy to make wrong moral judgments. Therefore, organizations can encourage and support the ethical behavior of leaders and members of the organization by formulating formal incentive mechanisms and standardized restraint mechanisms to prevent LIBOR fraud.

On the one hand, monetary incentives are a major factor in material rewards. Organizations can set up special cash rewards for reporting violations. When a company employee is found to be involved in interest rate manipulation or other violations, the reporter can directly report to the relevant department to verify the authenticity Then, the reporter will be rewarded directly in the form of cash. However, penalties such as deduction of wages, bonuses, fines, or expulsion are imposed on employees who violate the regulations based on the severity of the incident.

On the other hand, spiritual motivation is a higherlevel means to mobilize the enthusiasm of employees. Its motivation is deep and it lasts for a long time. For employees who dare to report manipulative behaviors, the company should not only provide positive material rewards, but also give them free commendations so that they can be listed on the company's honor roll, so that the whistleblower can get the sense of accomplishment and justice that they deserve. For employees who violate the rules, the results of the handling shall be reported to the whole company, and the punishment can also serve as a psychological warning to other employees.

\subsection{Prevent fraud in general}

The strength of the company's internal control ability is the essential factor to prevent fraud. Barclays Bank's serious manipulation of LIBOR interest rate is due to the weak internal control ability of the bank. Through the methods described above, such as enhancing employees' moral sense, moral leadership at all levels of management, actively promoting positive corporate culture and constantly improving various internal systems etc, the company's internal control ability can be continuously enhanced, so as to prevent the recurrence of fraud.

\section{RESPONSIBLE PARTIES}

Responsibility is also one of the important internal factors affecting interest rate manipulation. The sense of responsibility as an individual's due diligence to others [16]. Here, due diligence refers to fulfilling the responsibilities stipulated by law and morality, as well as the responsibilities corresponding to individual and social roles. Throughout the scandal, market regulators, executives and traders in Barclays Bank all lack of sense of responsibility. 
At the government level, the British government regulators successively received questions from the Federal Reserve Bank of New York, Wall Street Magazine and other institutions on the LIBOR interest rate after 2007, but did not pay attention to it in time. The government neither improved the LIBOR formation mechanism, nor took measures to prevent Barclays Bank's interest rate manipulation behavior, and it was not until 2012 that it began an investigation. Obviously, as an official government agency, it has not fulfilled the corresponding legal and social responsibilities. Instead, it has condoned the manipulation of banks to a certain extent. The lack of responsibility of the regulatory agencies has a negative impact on social organizations and governments around the world.

At the organizational level, Barclays' leadership still ordered the manipulation of LIBOR interest rates on the premise of knowing the wrong behavior in manipulating interest rates, in order to create the illusion of a good company's economy and to earn more benefits for the company, without considering the impact of the event on ordinary investors, financial markets and the whole society. Such behavior is totally lack of responsibility.

At the individual level, traders' dividends are linked to the winning or losing of the transaction, and the profit and loss of the trading day can be determined by the difference of several basis points in LIBOR. Therefore, traders have sufficient motives for fraud driven by profits. Coupled with the above-analyzed reasons such as the lack of supervision system and the acquiescence of the leadership, traders' subjective perception of responsibility and sentiment of responsibility have declined, thus committing illegal acts of responsibility.

\subsection{Responsibility of Individuals}

At staff level, first, there are often many participants in fraud incidents. Taking Barclays Bank in the LIBOR incident as an example, the completion of fraud requires the cooperation of different departments, leaders, and grassroots traders. Therefore, when a company colleague or superior leader asks you to commit fraud, the responsibility of an employee is to avoid ethical dilemmas and strictly refuse to work with the fraud team. Second, In a complex business environment, individuals should always maintain correct ethics and a strong sense of responsibility. After discovering frauds, various channels (such as superior leaders, government regulatory agencies, and social media) should be reasonably used to report them in a timely manner.
Avoid the development of laissez-faire fraud, which will eventually bring serious consequences to the organization and society.

At manager level, leaders are often the moral and behavioral imitation objects of their followers [17]. Leaders should take the initiative to establish a personal image of integrity, rigor, and responsibility. And play a proactive leading role within the company. Then use its moral leadership to guide the ethics of management employees, so that employees have an objective reference object when facing moral dilemmas, and help employees make correct ethical choices. Besides, No organization can avoid fraud [18]. Organizational leadership should always be vigilant and use organizational resources (internal audit function) to identify internal fraud risks. And take appropriate actions to ensure that control measures are in place to prevent and detect fraud. When cooperating with external parties, managers should be defensive and maintain a trusting but verifying attitude. Ensure that the internal organization is not affected by external influences and fraud occurs during cooperation.

\subsection{Responsibility of Organizations}

The three factors for fraud are: motivation, which means that someone has a reason to cheat; rationalization, which means that someone thinks it can be cheated; opportunity, which means that someone can cheat and may not be discovered. Motivation and rationalization are factors beyond the control of an organization. These factors are usually the result of external influences, personal life, and personal character. Opportunity is a factor that an organization can control. Therefore, the responsibility of the organization is to reduce until the elimination of the opportunity to commit fraud, and to create an environment that does not condone fraud through a strict company system and a positive company culture [19].

\subsection{Responsibility of Government}

The government has the right to formulate laws and supervise organizations from all walks of life, and the obligation to be responsible for the public. Therefore, it is the government's duty to regulate the financial market by continuously improving the legal provisions of the financial industry and maintaining strong market supervision for a long time.

At the same time, the government should strengthen the official audit function. The results of external official audits can be compared with the data 
of the company's internal audit department to ensure the accuracy of the audit results. On the one hand, professional auditors are usually proficient in assessing the possibility of fraud, errors and noncompliance, and can review the effectiveness of the company's internal controls, preventing individual organizations from deliberately hiring unprofessional internal auditors to manipulate audit results. On the other hand, as the auditors of official institutions, they are directly employed by the government, without the influence and threats of the management, which can ensure the authenticity of the audit results.

\section{AUTHORS' CONTRIBUTIONS}

Today, the countdown to LIBOR's withdrawal has sounded, but the enlightenment that the previous scandal has brought us is still useful.

Good corporate governance not only requires companies to comply with laws and international standards, but also to prevent corruption and bribery, and to ensure that corporate behavior conforms to ethical standards and business principles. Through the LIBOR scandal, we should realize that even if severe penalties cost the offenders, and even if the regulatory gap can be filled in to avoid the same violations, it is not possible to completely change the culture of an industry overnight. Only by completely changing the greedy culture within the bank and reshaping the correct corporate values, will the banking industry's misconduct scandals not repeat itself.

Only when individuals, organizations, and governments work together and shoulder their due responsibilities can we truly improve society's trust in the financial industry and prevent scandals like LIBOR from happening again.

\section{REFERENCES}

[1] J. R. Rest. Moral development: Advances in research and theory. New York: Praeger, 1986.

[2] A. W. Gouldner, "The norm of reciprocity: A preliminary statement," American Sociological Review., vol. 25, pp. 161-178, 1960.

[3] P. M. Blau. Exchange and power in social life. New York: John Wiley, 1964.

[4] S. E. Asch. Effects of group pressure upon the modification and distortion of judgments, in groups, leadership, men. Carnegie Press: Pittsburgh, 1951.

[5] R. Morck, "Behavioral Finance in Corporate
Governance-Independent Directors , NonExecutive Chairs, and the Importance of the Devil's Advocate," National Bureau of Economic Research., 2004, doi: 10.3386/w10644.

[6] S. Miller, The LIBOR Scandal: Culture, corruption and collective action problems in the global banking sector. In Integrity, risk and accountability in capital markets: regulating culture. Oxford: Hart Publishing, 2013.

[7] S. Irwin, What type of society is Britain today?: Lay perceptions of inequality [Internet], 2016 [updated 2016: cited 2021 August 16], Available from:

https://blogs.lse.ac.uk/politicsandpolicy/layperceptions-of-inequality/

[8] K. Brian, OECD insights income inequality the gap between rich and poor: The gap between rich and poor. Paris: OECD Publishing, 2015.

[9] M. Goldfarb, England's shrinking middle class struggles to hold on [Internet], 2013 [updated 2013: cited 2021 August 16], Available from: https://www.pri.org/stories/2013-0204/englands-shrinking-middle-class-struggleshold

[10] A. Chandler, Strategy and Structure. Cambridge: MIT Press, 1962.

[11] Z. Iscenko, C. Pickard, L. Smart, and Z. Vasas, "Behaviour and Compliance in Organisations," FCA Occasional Paper., no. 24, 2016.

[12] H. Aarts, P. M. Gollwitzer, and R. R. Hassin, "Goal contagion: perceiving is for pursuing," Journal of personality and social psychology, vol. 87, no. 1, pp. 23, 2004

[13] V. Burksiene, J. Dvorak, and G. Burbulytetsiskarishvili, "Sustainability and sustainability marketing in competing for the title of European Capital of Culture," Organizacija, vol. 51, no. 1, 2018.

[14] T. Noe, A survey of the economic theory of reputation: Its logic and limits. Oxford: Oxford handbook of corporate reputation, 2012.

[15] S. Blomskog. “An Evaluation of Employee Performance Based on Imprecise Value Judgments: Two Experiments," Södertörns högskola., 2007.

[16] B. R. Schlenker, T. W. Britt, J. Pennington, R. Murphy, and K. Doherty. "The triangle model of 
responsibility," Psychological review., vol. 101, no. 4, pp. 632, 1994.

[17] E. P. Hollander. "Ethical challenges in the leaderfollower relationship," Business Ethics Quarterly, pp. 55-65, 1995.

[18] S. Haugen, and J. R. Selin. "Identifying and controlling computer crime and employee fraud," Industrial Management \& Data Systems, vol 99, no. $8, \quad$ pp. 340-344, 1999, https://doi.org/10.1108/02635579910262544

[19] Bakertilly, Fraud: Who is responsible? [Internet], 2013 [updated 2013: cited 2021 August 16], Available from: https://www.bakertilly.com/insights/fraud-whois-responsible 